\title{
Response to fever and utilization of standby emergency treatment (SBET) for malaria in travellers to Southeast Asia: a questionnaire-based cohort study
}

Christof D. Vinnemeier ${ }^{1,2}$, Camilla Rothe ${ }^{1}$, Benno Kreuels ${ }^{1,3}$, Marylyn M. Addo ${ }^{1}$, Sabine Vygen-Bonnet ${ }^{4}$, Jakob P. Cramer ${ }^{2}$ and Thierry Rolling ${ }^{1,2^{*}}$

\begin{abstract}
Background: Guidelines in several European countries recommend standby emergency treatment (SBET) for travellers to regions with low or medium malaria transmission instead of continuous chemoprophylaxis: travellers are advised to seek medical assistance within $24 \mathrm{~h}$ in case of fever and to self-administer SBET only if they are not able to consult a doctor within the time period specified. Data on healthcare-seeking behaviour of febrile travellers and utilization of SBET is however scarce as only two studies were performed in the mid-1990s. Since tourism is constantly increasing and malaria epidemiology has dramatically changed in the meantime more knowledge is urgently needed.

Methods: Some 876 travellers to destinations in South and Southeast Asia with low or medium malaria transmission were recruited in the travel clinic of the University Medical Center Hamburg-Eppendorf. Demographic and travelrelated data were collected by using questionnaires. Pre-travel advice was carried out and SBET was prescribed in accordance to national guidelines. Post-travel phone interviews were performed to assess health incidents during travel and individual responses of travellers to febrile illness.

Results: Out of 714 patients who were monitored, 130 (18\%) reported onset of fever during travel or 14 days after return. Of those travellers who reported fever, 100 (80\%) carried SBET during travel. The vast majority of 79 (79\%) febrile travellers who carried SBET did not seek medical assistance. Overall, 14 (14\%) febrile patients who carried SBET and six (20\%) patients who did not carry SBET took the correct measure (doctor visit or timely SBET administration) as a response to febrile illness, respectively. Only two travellers self-administered SBET, but both of them applied the wrong regimen.

Conclusions: In view of declining malaria transmission and improving medical infrastructure in most countries of Southeast Asia and obvious obstacles concerning SBET as shown in this study the current strategy should be re-evaluated. Pre-travel advice concerning malaria in SEA should focus on appropriate mosquito bite protection and clearly emphasize the need to see a doctor within $24 \mathrm{~h}$ after onset of fever.
\end{abstract}

Keywords: Malaria, Standby emergency treatment, SBET, Southeast Asia, Travellers, Healthcare-seeking behaviour, Malaria guidelines, Pre-travel advice

\footnotetext{
*Correspondence: t.rolling@uke.de

${ }^{1}$ I. Department of Medicine, Section Tropical Medicine, University Medical

Center Hamburg-Eppendorf, Hamburg, Germany

Full list of author information is available at the end of the article
} 


\section{Background}

National recommendations for malaria prophylaxis for travellers to low- or intermediate-risk areas vary. Depending on seasonality, mode of travel, length of stay, travellers are advised to perform mosquito protection and chemoprophylaxis or carry standby emergency treatment (SBET). SBET is a concept according to which travellers carry anti-malarials (e.g., atovaquone/proguanil or artemether/lumefantrine), which have to be self-administered in case of fever and the inability to rule out malaria as the cause of fever within $24 \mathrm{~h}$. The rationale behind the strategy of SBET is that the potential occurrence of side effects during continuous chemoprophylaxis might outweigh the relatively small risk of developing malaria in areas of low malaria transmission. The continuous decrease in malaria incidence in many low-transmission areas, e.g., in South- and Southeast Asia (SEA), as well as increasing drug resistance have also served as arguments in favour of SBET. The Societies for Tropical Medicine of Germany and Switzerland, for example, promote SBET for all areas of low and medium malaria transmission along with protection against mosquito bites instead of chemoprophylaxis [1]. The World Health Organization (WHO) recommends this approach to travellers "in some occupational groups who make frequent short stops in countries or areas with malaria risk over a prolonged period of time" and short-term travellers to "remote rural areas where there is very low risk of infection" [2]. The Centers for Disease Control and Prevention (CDC) in the USA, in contrast, recommend to carry SBET to ensure high-quality treatment in case of a diagnosis of malaria, accounting for the increasing numbers of fake antimalarials in some countries of SEA [3].

While the concept of SBET appears straightforward in theory, it is unclear whether or not travellers are willing or able to apply SBET correctly while being abroad. In fact, there has been repeated criticism that travellers may be unable to make correct decisions in case of onset of fever during travel and tend to apply medication incorrectly $[4,5]$. To date only two publications from 1995 are available concerning these issues. Both studies demonstrated that only a small fraction of travellers had to self-administer SBET. Additionally, when Plasmodium falciparum antibody levels were assessed in all travellers after return it turned out that even this low number of self-administrations proved to be a massive overuse of SBET, since most SBET users had no antibodies $[4,6]$.

Moreover, the SBET concept is based on the assumption that reliable medical care is generally not available at malaria-endemic tourist destinations. Yet, infrastructure for tourism, as well as medical emergency care has improved significantly in the past decades in many countries of SEA. At the same time, numbers of travellers to those regions have increased substantially due to a major surge in the availability of flight connections as well as a dramatic decrease in airline fares [7]. Concurrently to increased travel, malaria transmission in most parts of SEA has decreased, resulting in smaller numbers of imported malaria from the region $[8,9]$. India also recorded a decline in malaria cases, but predominantly through control of falciparum malaria. In contrast, the relative proportion of Plasmodium vivax cases was increasing on the Indian sub-continent [10].

The aim of the present study was to assess utilization of SBET in the face of changing background conditions. Therefore, a cohort study in a population travelling to areas of low and medium malaria transmission in South Asia and SEA was performed.

\section{Methods}

\section{Study design and recruitment}

Between October 2013 and November 2014, a prospective, questionnaire-based cohort study was conducted at the travel clinic of the University Medical Center Hamburg-Eppendorf. Travellers aged $\geq 18$ years with intention to travel to South Asia and SEA were screened for eligibility in the waiting area prior to seeing a trained physician for travel medicine advice. The following destination countries were defined for participation: India, Thailand, Laos, Cambodia, Vietnam, Sri Lanka, Myanmar, Indonesia, Bangladesh, the Philippines, or Malaysia. Additional inclusion criteria were travel duration between 7 days and 12 weeks and willingness to provide contact data for a post-travel interview as well as signed informed consent to participate. Study procedures comprised completion of a pre- and post-travel questionnaire.

\section{Pre-travel interview}

The pre-travel questionnaire had to be completed before travel medicine consultation with a physician. The pretravel questionnaire comprised questions concerning the travel destination, mode of travel and basic health data of the participant, such as pre-existing illness and regular medication. To avoid a possible behavioural bias of study participants regarding the awareness of fever or application of SBET, participants were informed that a post-travel telephone interview would be conducted concerning health incidents during and after travel without specifying precise question items or topics.

Standby emergency treatment was prescribed according to the current recommendations of the German Society of Tropical Medicine (DTG) for the years 2013/2014 [1]. In brief, the DTG advised travellers to all countries, except certain regions in Indonesia, to carry out mosquito bite prevention at all times and to carry SBET, such as atovaquone/proguanil or artemether/lumefantrine. 
For regions in Indonesia located east of Bali, travellers were advised to take continuous chemoprophylaxis either with atovaquone/proguanil or mefloquine.

Use of SBET was thoroughly explained, travellers were advised to take a thermometer with them and administer SBET only in case of fever with temperatures of $>38{ }^{\circ} \mathrm{C}$ and if they were unable to seek medical advice within $24 \mathrm{~h}$. Fever, chills, myalgia, and symptoms suggestive of a common cold were mentioned as key symptoms to prompt travellers to seek medical advice. Additionally, a leaflet with all instructions was handed out to all participants. Participation in the study did not influence recommendations of preventive measures against mosquito bites, vaccinations or prescription of SBET.

\section{Post-travel interview}

Between 4 and 6 weeks after travellers had returned home, all participants were contacted by a trained member of the study team to be screened for participation in the post-travel interview by asking the following four questions:

1. Did you experience fever, chills or flu-like symptoms during your travelling abroad or within 14 days after returning home?

2. Did you consult a doctor during your travelling abroad or within 14 days after returning home?

3. Did you or somebody from your travel group carry any anti-malarial medication (e.g., mefloquine, atovaquone/proguanil, doxycycline, artemether/ lumefantrine) or buy one in the destination country?

4. Did you self-administer any anti-malarial medication?

If one of these questions was answered with "Yes", travellers qualified for participation in the detailed posttravel questionnaire concerning symptoms, date and place of onset of symptoms, doctor visit, diagnosis and medication.

\section{Data analysis}

Data analysis was carried out by using Stata v11.1 (StataCorp, College Station, TX, USA). Data analysis was descriptive and no statistical hypothesis was tested.

\section{Notification data on malaria}

To define the context in which standby emergency treatment is currently used in Germany, notification data of malaria cases from the destination countries covered by the study were analysed. In Germany, notification of malaria cases by laboratories is mandatory and based on the direct detection of the malaria parasite in the human blood. The diagnosing laboratory reports directly to the
Robert Koch Institute (RKI). A second data form with information on travel destinations and purposes, clinical findings, prophylaxis, and treatment is completed by the attending physician. The department of infectious disease epidemiology of the RKI joins the information of both data forms in a unique database and analyse the data on an annual basis. Despite the mandatory nature, notification data are incomplete: not all cases are reported; for some cases the RKI receives only one of the two data forms; some of the data forms are only partially filled out.

\section{Ethical considerations}

The study protocol was approved by the ethics committee of the Medical Council in Hamburg, Germany. Prior to recruitment and pre-travel advice, eligible travellers were informed about the study by a member of the study team. They were included only after providing written informed consent.

\section{Results \\ Characteristics of travellers and itineraries}

Out of 1671 travellers screened for eligibility, pre-travel questionnaires were completed by 876 travellers with a median age of 32 years [interquartile range (IQR) 17-45]. Gender distribution was about equal ( $52.7 \%$ women). The majority of participants were well educated, more than half (53.9\%) of them held a university degree. Pre-existing illness was reported by only a minor proportion of $14.6 \%$ of study participants. Thyroid disease and chronic respiratory diseases accounted for the most frequent disorders with 2.5 and $2.1 \%$, respectively. Cardiac disease and diabetes were stated by eight $(0.9 \%)$ and five $(0.6 \%)$ of travellers. More than a quarter of travellers reported carriage of regular medication such as contraceptives (8.6\%), drugs related to thyroid disease $(4.9 \%)$ or hypertension (2.8\%) (Table 1).

Thailand (35.6\%), Vietnam (25.5\%) and Cambodia (20.8\%) were the most popular destinations. The median duration of travel was 21 days (IQR: 21-28). Top reason for travel was tourism, almost three-quarters of travellers intended to travel independently, i.e., without any kind of guidance. Only $32.4 \%$ of study participants had never travelled to (sub-) tropical regions before (Table 2).

\section{Post-travel}

Of the 876 travellers recruited before travel, 714 could be contacted via telephone for a post-travel interview. Amongst these, 130 (18.2\%) reported onset of fever during travel or within 14 days after return. Of these, 31.5\% reported concomitant diarrhoea, $14.6 \%$ reported vomiting. Myalgia, chills and other flu-like symptoms were reported by $47.7 \%$ (Table 3 ). 
Table 1 Characteristics of travellers to Southeast Asia ( $n=876)$

\begin{tabular}{|c|c|c|}
\hline Travellers' characteristics & & IQR \\
\hline Age (median) & 32 & $18(27-45)$ \\
\hline Travellers' characteristics & $\mathbf{n}$ & $\%$ \\
\hline \multicolumn{3}{|l|}{ Sex } \\
\hline Male & 414 & 47.3 \\
\hline Female & 462 & 52.7 \\
\hline \multicolumn{3}{|l|}{ Education } \\
\hline Tertiary degree & 515 & 58.8 \\
\hline Upper secondary degree & 212 & 24.2 \\
\hline Lower secondary degree & 133 & 15.2 \\
\hline Primary & 16 & 1.8 \\
\hline \multicolumn{3}{|l|}{ Pre-existing illness } \\
\hline Any & 128 & 14.6 \\
\hline Thyroid disease & 22 & 2.5 \\
\hline Chronic respiratory diseases & 18 & 2.1 \\
\hline Allergies & 13 & 1.5 \\
\hline Hypertension & 11 & 1.3 \\
\hline Neurologic disorders & 11 & 1.3 \\
\hline Cardiac diseases & 8 & 0.9 \\
\hline Diabetes mellitus & 5 & 0.6 \\
\hline Other & 61 & 6.9 \\
\hline \multicolumn{3}{|l|}{ Medication } \\
\hline Any & 260 & 26.3 \\
\hline Other & 95 & 10.8 \\
\hline Contraceptive & 75 & 8.6 \\
\hline Thyroid medication & 43 & 4.9 \\
\hline Antihypertensives & 25 & 2.8 \\
\hline Antiplatelet drugs & 12 & 1.4 \\
\hline Drugs for respiratory diseases & 10 & 1.1 \\
\hline
\end{tabular}

IQR interquartile range

\section{SBET utilization}

Overall, 511 (71.6\%) travellers carried SBET during travel. Out of 130 febrile travellers, 100 (76.9\%) carried SBET during travel. Amongst those febrile travellers who carried SBET, 21 (21\%) attended a local medical care facility because of the fever, only 14 (14\%) of those within $24 \mathrm{~h}$ after onset of fever. Only 2 out of 714 travellers self-administered SBET in terms of emergency medication, but did not apply the correct scheme (Fig. 1). A 25-year old male traveller to Malaysia and Indonesia stated to have mistakenly applied one tablet of atovaquone/proguanil during his stay in Malaysia due to "lack of knowledge". After his return to Germany he experienced fever, chills and diarrhoea and consulted a doctor who diagnosed an infection with Salmonella spp.

Another 45-year old traveller to India experienced fever, diarrhoea and flu-like symptoms on his 21st day of travel. He did not attend a medical facility, but selfadministered one tablet of atovaquone/proguanil seven days after onset of the symptoms, while he was staying in Kolkata/India (Table 4).

Out of 30 febrile travellers not carrying SBET during travel, nine $(30 \%)$ visited a healthcare facility after the onset of fever, six of those within $24 \mathrm{~h}$. Overall, 14 travellers (14\%) experiencing fever during travel followed instructions as recommended by pre-travel advice by carrying SBET and visiting a health care facility within $24 \mathrm{~h}$. None of the 14 travellers visiting a clinic for fever, took SBET, since malaria was ruled out at the health facility. Among travellers who did not experience fever during travel, no one self-administered SBET as emergency medication.

\section{Recorded cases of imported malaria from South Asia and SEA}

Table 5 shows the distribution of notified imported malaria cases from South Asia and SEA to Germany between 2011 and 2015. Throughout this period, most travellers with malaria returned from India and Indonesia, while no malaria was imported from Myanmar and Laos. The majority of notified cases was attributable to $P$. vivax infections (46.6\%), while only $13(17 \%)$ cases of $P$. falciparum were notified.

\section{Discussion}

A substantial proportion of $18 \%$ of travellers to regions of South Asia and SEA with medium and low risk for malaria transmission reported febrile illness during travel. Only very few travellers adhered to the pre-travel advice to seek medical support within $24 \mathrm{~h}$ in case of fever. Only 2 out of 714 travellers self-administered SBET during travel, but both of them applied an incorrect regimen and took a single tablet only, which would not have any therapeutic effect in case of true malaria. The study team is not aware of any case of malaria in the study population.

In assessing the concept of SBET, three main problems were identified in travellers with fever during travel: (i) a major proportion of travellers did not carry SBET although it was prescribed; (ii) non-adherence to pretravel advice while being abroad; and, (iii) incorrect selfadministration of SBET.

Travellers recruited for this study were young with a median age of 32 years, healthy, disproportionally well educated and the majority was proficient with travelling to (sub-) tropical countries. In this respect characteristics of this population are comparable to those from other studies and it seems justifiable to assume, that the current results can be generalized to other traveller populations attending pre-travel clinics $[11,12]$. 
Table 2 Itinerary characteristics $(n=876)$

\begin{tabular}{|c|c|c|}
\hline Itinerary characteristics & & IQR \\
\hline Duration of travel (days) & 21 & $7(21-28)$ \\
\hline Itinerary characteristics & $\mathrm{n}$ & $\%$ \\
\hline \multicolumn{3}{|l|}{ Destination } \\
\hline Thailand & 312 & 35.6 \\
\hline Vietnam & 223 & 25.5 \\
\hline Cambodia & 182 & 20.8 \\
\hline India & 166 & 18.9 \\
\hline Indonesia & 150 & 17.1 \\
\hline Malaysia & 93 & 10.6 \\
\hline Laos & 87 & 9.9 \\
\hline Sri Lanka & 74 & 8. \\
\hline Myanmar & 53 & 6. \\
\hline Philippines & 48 & 5.5 \\
\hline \multicolumn{3}{|l|}{ Reason for travel } \\
\hline Tourism & 796 & 91.5 \\
\hline Business & 29 & 3 \\
\hline Volunteering/education & 30 & 3. \\
\hline Visiting friends and relatives (VFR) & 15 & 1.7 \\
\hline Other & 6 & 0.7 \\
\hline \multicolumn{3}{|l|}{ Type of travel } \\
\hline Backpacking & 340 & 38. \\
\hline Individual travelling & 306 & 34 \\
\hline Organized round trip & 120 & 13.7 \\
\hline Package holiday & 26 & 3.0 \\
\hline Ship cruise & 14 & 1. \\
\hline No answer & 70 & 8 \\
\hline \multicolumn{3}{|l|}{ Previous travel experience } \\
\hline $1-2$ times & 285 & 32.5 \\
\hline 3 to -5 times & 169 & 19.3 \\
\hline$>5$ times & 134 & 15 \\
\hline None & 284 & 32. \\
\hline No answer & 4 & \\
\hline
\end{tabular}

IQR interquartile range

Despite the changed landscape of malaria since 1995 when the last data on SBET utilization was published, the findings are in line with the prior studies. In a Swiss study from 1995, only six (0.5\%) out of 123 febrile travellers applied SBET and only four of them applied the correct regimen [4]. In a German multi-centre study, $1.4 \%$ (40/2867) of travellers reported SBET use. Malaria antibody levels were later demonstrated in four participants who applied SBET [6]. Increasing evidence therefore indicates that only a small proportion of travellers to low risk malaria areas adheres to pre-travel advice based on the SBET concept.

The low acceptance and carriage rate of SBET in this study population is however surprising. Only $16 \%$ of travellers carrying SBET took any correct measure and
$20 \%$ of travellers not carrying SBET sought medical assistance after the onset of fever which is a strikingly low figure regarding the standardized pre-travel advice and the educational level of the study population. Explanations for this result may be various: available data suggest that the recall rate of information after medical consultations showed overall good results suggesting that key messages seem to be well captured [13-15]. Since most consultations incorporate one or more vaccinations, injection anxiety, which has been shown quite common in some populations could be a potential distractor $[16,17]$. However, the only available study in this context showed no association between recall of information and injection anxiety [18]. In any case, provision of simplified key messages after vaccination may facilitate better recognition of information. In general, studies assessing a traveller's knowledge about travel-related health issues underlined a general increase of knowledge after pre-travel advice, so that other factors are likely to have contributed to nonadherence to emergency measures in case of fever in the current study [19-21]. In particular, in areas where population density and accessibility to medical facilities is good, tourists might tend to delay the decision to consult a doctor in favour of waiting for spontaneous recovery. Carriage of SBET could further encourage travellers to defer a medical consultation thereby waiting for the fever to drop. Challenges in adherence are not limited

Table 3 Symptoms of travellers reporting fever during travel or 14 days after return $(n=130)$

\begin{tabular}{llc}
\hline Fever & $\mathbf{n}$ & \% \\
\hline Yes & 130 & 18.2 \\
$\quad$ Uring their travel & 89 & 68.5 \\
$\quad$ Ithin 14 days after return & 41 & 31.5 \\
No & 559 & 78.3 \\
No answer & 25 & 3.5 \\
\hline Additional symptoms & $\mathbf{n}$ & $\mathbf{\%}^{\mathbf{a}}$ \\
in febrile patients $\mathbf{( n = 1 3 0 )}$ & & \\
\hline Diarrhoea & 41 & 31.5 \\
Myalgia & 31 & 23.8 \\
Chills & 27 & 20.8 \\
Headache & 21 & 16.1 \\
Vomiting & 19 & 14.6 \\
Sore throat & 17 & 13.1 \\
Abdominal pain & 15 & 11.5 \\
Tiredness & 12 & 9.2 \\
Stomache ache & 8 & 6.2 \\
Flu-like symptoms & 4 & 3.1 \\
Vertigo & 3 & 2.3 \\
Symptoms of sinusitis & 3 & 2.3 \\
\hline
\end{tabular}

a May not sum up to $100 \%$ since some patients recalled multiple symptoms 


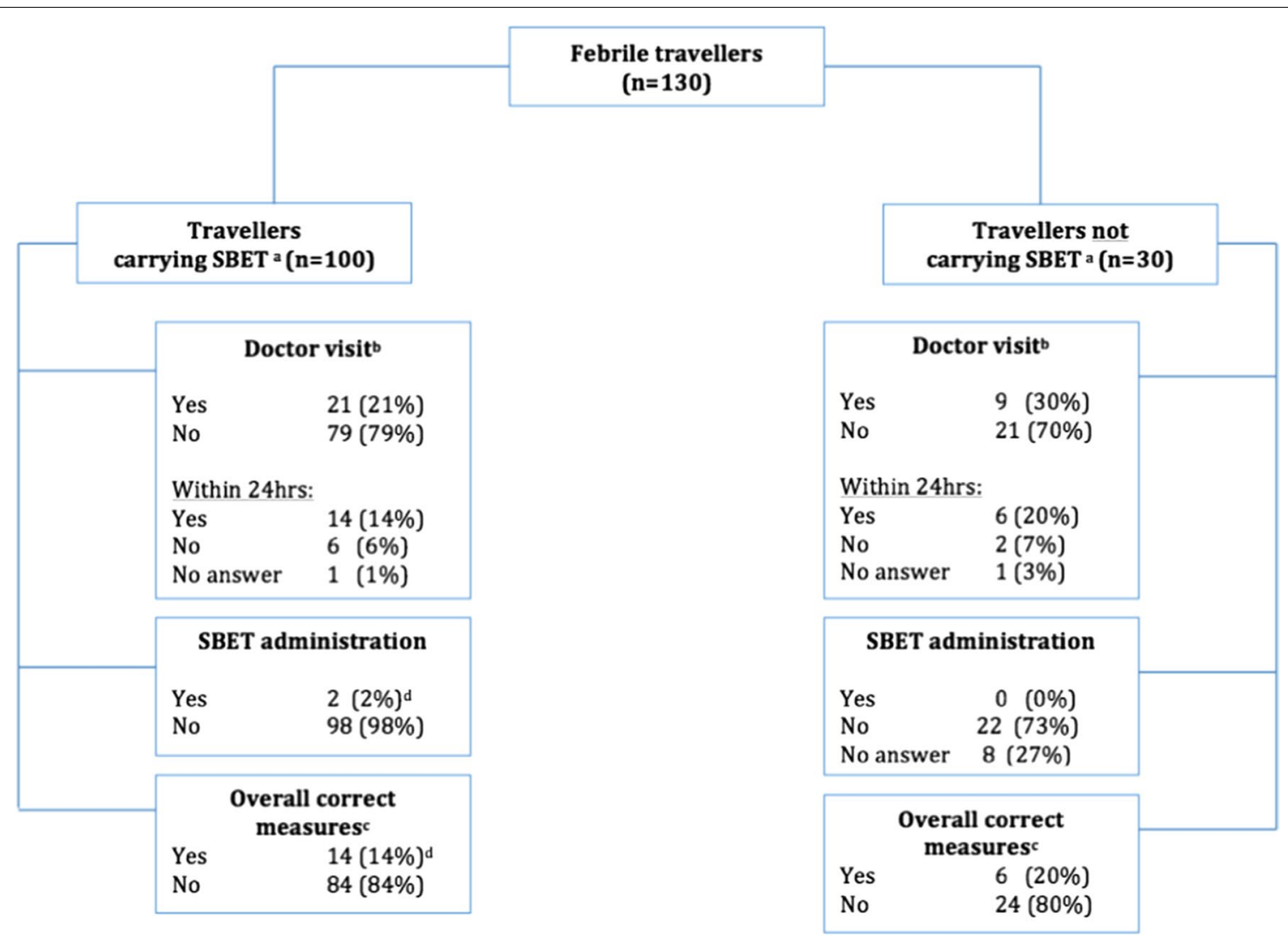

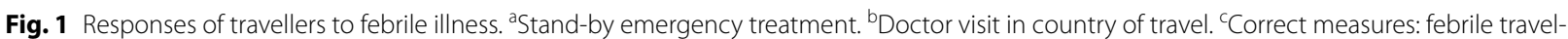
lers took correct measures if they sought for medical assistance within $24 \mathrm{~h}$ or self-administered SBET. ${ }^{\mathrm{d}}$ Since both travellers applied an incorrect scheme of SBET, administration of the medication was not counted as "correct measure"

Table 4 Febrile travellers self-administering SBET $(n=2)$

\begin{tabular}{|c|c|c|c|c|c|}
\hline $\begin{array}{l}\text { Sex, } \\
\text { age (years) }\end{array}$ & Destination & Complaints & $\begin{array}{l}\text { Consultation } \\
\text { of doctor }\end{array}$ & $\begin{array}{l}\text { Place of SBET } \\
\text { administration }\end{array}$ & $\begin{array}{l}\text { Correct } \\
\text { regimen }\end{array}$ \\
\hline Male, 25 & Malaysia, Indonesia & Fever, chills, diarrhoea; onset after return to Germany & In Germany & Malaysia & No \\
\hline Male, 45 & India & Fever, diarrhoea, flu-like symptoms; onset travel day 21 & No & Kolkata, India & No \\
\hline
\end{tabular}

to the concept of SBET but are also seen for continuous malaria chemoprophylaxis for travellers to high-risk countries [22-26]. Several studies prove that the majority of returning travellers with malaria did not take malaria chemoprophylaxis or applied an incorrect regimen, the majority being travellers visiting friends or relatives (VFR) abroad [22, 27-31].

In consequence of an expanding tourism industry, travel to SEA is steadily increasing. For 2014, international tourist arrivals in the region rose to 96.7 million, which is a nearly fivefold increase since 1990 [7]. Concurrently to increasing travel, malaria transmission in South Asia and SEA has decreased over the past years. Between 2000 and 2015 the estimated number of malaria cases and deaths for the whole WHO region Southeast Asia declined by 39 and 37\%, respectively [32]. It has been argued before that the malaria risk for travellers is not correlated with infection rates in the local population and attack rates in visitors may likely be higher because of the absence of partial immunity in contrast to the local populations [33]. Recent studies confirmed the trend of decreasing cases of imported malaria cases from SEA [9, 34]. According to data from malaria surveillance reports from the USA and 12 European countries, malaria cases imported from countries of SEA declined by $47 \%$ between 2003 and 2008 [8]. Another assessment of 320 imported cases of malaria between 1994 and 2012 from Denmark showed an annual decline of 6.5\% [35]. 
Table 5 Reported cases of malaria imported into Germany from SEA between 2011 and 2014

\begin{tabular}{|c|c|c|c|c|c|c|}
\hline & 2011 & 2012 & 2013 & 2014 & 2015 & Total \\
\hline \multicolumn{7}{|l|}{ Country of travel } \\
\hline Myanmar & 0 & 0 & 0 & 0 & 0 & 0 \\
\hline India & 17 & 17 & 1 & 5 & 5 & 45 \\
\hline Indonesia & 4 & 1 & 1 & 1 & 2 & 9 \\
\hline Cambodia & 1 & 0 & 0 & 1 & 2 & 4 \\
\hline Laos & 0 & 0 & 0 & 0 & 0 & 0 \\
\hline Malaysia & 0 & 0 & 0 & 0 & 1 & 1 \\
\hline Philippines & 0 & 0 & 0 & 0 & 1 & 1 \\
\hline Sri Lanka & 0 & 0 & 1 & 0 & 0 & 1 \\
\hline Thailand & 0 & 1 & 3 & 1 & 2 & 7 \\
\hline Vietnam & 0 & 0 & 0 & 1 & 0 & 1 \\
\hline Not specified & 2 & 5 & 1 & 0 & 0 & 8 \\
\hline \multicolumn{7}{|l|}{ Plasmodium species } \\
\hline Total (all species) & 24 & 24 & 7 & 9 & 13 & 77 \\
\hline Plasmodium falciparum & 0 & 5 & 1 & 3 & 4 & 13 \\
\hline Plasmodium vivax & 18 & 15 & 4 & 4 & 5 & 46 \\
\hline Other and non-specified & 1 & 1 & 2 & 1 & 1 & 6 \\
\hline
\end{tabular}

Cases reported to the Robert Koch Institute Berlin, Germany

However, India and Indonesia, as it is the case with notification data in Table 5, constitute two of the main source countries for imported malaria. In a retrospective analysis of national notification data from Canada, 9.2\% of imported malaria cases originated from India. India displayed the most common source country for vivax malaria cases [36]. Whilst this should be taken into account during pre-travel advice, the notification data to the RKI presented in this study show low and declining numbers of malaria cases imported from South and SEA to Germany. Indeed, these data underline the economical impact of over-prescription of SBET, if compared to the annual numbers of travellers to SEA. Using figures provided by the German Travel Association (DRV), $1,769,825$ individuals travelled to countries considered in this study in 2015 [37]. Considering a price of 42 Euro per unit, this would translate to 71.4 million Euros spent for SBET in 2015 in Germany alone. Facing the low number of imported falciparum malaria (13 cases during the past 5 years), these expenses hardly pass any cost-benefit analysis. In the light of the decreased numbers of imported malaria and the fact that the majority of reported cases are $P$. vivax cases, strategies for travellers to these regions have to be reassessed, in particular, because relapse of $P$. vivax is not adequately prevented by regular chemoprophylaxis or treated by a standard regimen of standby emergency treatment.

Even though atovaquone/proguanil is generally considered safe, up to $82 \%$ of patients reported an adverse event $[38,39]$. The benefit-risk ratio for continuous malaria chemoprophylaxis is consecutively very low for most regions in SEA, and does not pose a viable alternative [40]. However, data from the current study reinforce the assumption that SBET has to be critically assessed. Equipping travellers with an anti-malarial has the potential to lead to a false sense of security and an uncritical perception of the risk of malaria during travel, favouring short-sleeved clothes and avoidance of repellents. Unattended administration of SBET harbours the risk of missing other medical conditions. The vast majority of travellers sojourn on popular tourist routes and visit similar places at their destinations. During the past two decades healthcare systems in most countries of South Asia and SEA have improved, although they remain at a low standard. However, from the main tourist tracks medical facilities can usually be reached within $24 \mathrm{~h}$, particularly in metropolitan areas. One of the male travellers in this study who used SBET started intake of medication in Kolkata, where it would easily have been possible to find a hospital to rule out malaria [21]. There are however arguments in favour of SBET. First, travellers have advanced to more remote areas worldwide and carriage of SBET can be life-saving in cases when travellers are unable to reach a health facility due to missing infrastructure or external factors, e.g., severe weather conditions. Secondly, carriage of high-quality medication ensures safe treatment in view of increasing numbers of fake anti-malarials, especially in Asia [41-43]. Third, studies have shown that long-term travel can result in a higher cumulative risk for malaria [44, 45]. Those travellers may benefit from provision of SBET 
given the assumption that they tend to visit more rural regions. However, it is not possible to support this recommendation with the current study data, since only individuals travelling for no longer than 12 weeks were recruited.

This study has some limitations to be taken into account. As described above, a selective population of travellers visiting a health facility for pre-travel advice was studied. This population may not be comparable to the overall population travelling to South Asia and SEA. Earlier data demonstrated that travellers who attended a travel clinic have better knowledge about potential risks and protective measures [46]. Yet unpublished data from the Hamburg Airport Survey also suggest that travellers in the overall population have less frequently attended a travel clinic and are less frequently carrying SBET. Finally, it was not possible to completely rule out malaria in returned travellers, since no serology for Plasmodium spp. was performed. However, conduct of phone interviews 4-6 weeks after return makes unrecognized episodes of clinically relevant malaria unlikely.

\section{Conclusions}

Only a very small proportion of travellers to low-risk malaria areas experiencing fever while abroad adhered to pre-travel advice related to the concept of SBET. Travel advice concerning malaria in South Asia and SEA should focus on appropriate mosquito bite protection and clearly emphasize the need to see a doctor within $24 \mathrm{~h}$ after onset of fever. Travellers with need of SBET should be carefully selected. Recommendations related to SBET should be revisited and limited to selected situations only, e.g., long-term travel or travel to remote rural areas.

\section{Authors' contributions}

CV, TR and JPC designed the study. CV and TR carried out statistical analyses and wrote the first draft of the manuscript. SVB contributed notification data from the Robert-Koch-Institute. CV, MMA, CR, JPC, TR, and BK recruited subjects to the study. All authors participated in writing the final draft. All authors read and approved the final manuscript.

\section{Author details \\ ${ }^{1}$ I. Department of Medicine, Section Tropical Medicine, University Medical Center Hamburg-Eppendorf, Hamburg, Germany. ${ }^{2}$ Clinical Research Group, Bernhard Nocht Institute for Tropical Medicine, Hamburg, Germany. ${ }^{3}$ Infec- tious Disease Epidemiology, Bernhard Nocht Institute for Tropical Medicine, Hamburg, Germany. ${ }^{4}$ Department for Infectious Disease Epidemiology, Robert Koch Institute, Berlin, Germany.}

\section{Acknowledgements}

We thank Prof. Gerd-Dieter Burchard (Bernhard-Nocht-Institute fort Tropical Medicine) for his critical review of the manuscript and the helpful comments. We also thank the Deutscher ReiseVerband e.V. (DRV), Berlin, for provision of German outbound flight data to countries of South and Southeast Asia.

\section{Competing interests}

JPC is an employee of Takeda Pharmaceuticals. Other authors declare that they have no competing interests.

\section{Availability of data and materials}

The datasets analysed during the current study are not publicly available due to participants' privacy issues. The datasets are available from the corresponding author on reasonable request.

\section{Funding}

This study was funded by intramural funding of the University Medical Centre Hamburg-Eppendorf. The funding body had no role in the design of the study, data collection, analysis, interpretation of data, and in writing the manuscript.

Received: 31 August 2016 Accepted: 4 January 2017

Published online: 25 January 2017

\section{References}

1. Deutsche Gesellschaft für Tropenmedizin (DTG). Empfehlungen zur Malariavorbeugung. 2014

2. World Health Organization (WHO). Health and International Travel 2012; Malaria: 2015 update—Chapter 7. http://www.who.int/ith/2015-ithchapter7.pdf?ua=1. Accessed 16 Dec 2016.

3. Centers for Disease Control and Prevention (CDC). Malaria information and prophylaxis. http://www.cdc.gov/malaria/travelers/country_table/a. html. Accessed 16 Dec 2016.

4. Schlagenhauf P, Steffen R, Tschopp A, Van Damme P, Mittelholzer ML, Leuenberger $\mathrm{H}$, et al. Behavioural aspects of travellers in their use of malaria presumptive treatment. Bull World Health Organ. 1995;73:215-21.

5. Voumard R, Berthod D, Rambaud-Althaus C, D'Acremont V, Genton B. Recommendations for malaria prevention in moderate to low risk areas: travellers' choice and risk perception. Malar J. 2015;14:139.

6. Nothdurft HD, Jelinek T, Pechel SM, Hess F, Maiwald H, Marschang A, et al. Stand-by treatment of suspected malaria in travellers. Trop Med Parasitol. 1995:46:161-3.

7. United Nations World Tourism Organization (UNWTO). Yearbook of Tourism Statistics. 2015 edn; 2015.

8. Behrens RH, Carroll B, Hellgren U, Visser LG, Siikamaki H, Vestergaard LS, et al. The incidence of malaria in travellers to South-East Asia: is local malaria transmission a useful risk indicator? Malar J. 2010;9:266.

9. Broderick C, Nadjm B, Smith V, Blaze M, Checkley A, Chiodini PL, et al. Clinical, geographical, and temporal risk factors associated with presentation and outcome of vivax malaria imported into the United Kingdom over 27 years: observational study. BMJ. 2015;350:h1703.

10. Anvikar AR, Shah N, Dhariwal AC, Sonal GS, Pradhan MM, Ghosh SK, et al. Epidemiology of Plasmodium vivax malaria in India. Am J Trop Med Hyg. 2016;95:108-20.

11. Buhler S, Ruegg R, Steffen R, Hatz C, Jaeger VK. A profile of travelers-an analysis from a large swiss travel clinic. J Travel Med. 2014;21:324-31.

12. Boubaker R, Meige P, Mialet C, Buffat CN, Uwanyiligira M, Widmer F, et al. Travellers' profile, travel patterns and vaccine practices - a 10-year prospective study in a Swiss Travel Clinic. J Travel Med. 2016;23:tav017.

13. Genton B, Behrens RH. Specialized travel consultation part II: acquiring knowledge. J Travel Med. 1994;1:13-5.

14. Teodosio R, Goncalves L, Atouguia J, Imperatori E. Quality assessment in a travel clinic: a study of travelers' knowledge about malaria. J Travel Med. 2006;13:288-93.

15. McGuinness SL, Spelman T, Johnson DF, Leder K. Immediate recall of health issues discussed during a pre-travel consultation. J Travel Med. 2015;22:145-51.

16. Fredrikson $M$, Annas $P$, Fischer $H$, Wik G. Gender and age differences in the prevalence of specific fears and phobias. Behav Res Ther. 1996;34:33-9.

17. Deacon B, Abramowitz J. Fear of needles and vasovagal reactions among phlebotomy patients. J Anxiety Disord. 2006;20:946-60.

18. Noble LM, Farquharson L, O'Dwyer NA, Behrens RH. The impact of injection anxiety on education of travelers about common travel risks. J Travel Med. 2014;21:86-91.

19. McIntosh IB, Reed JM, Power KG. Travellers' diarrhoea and the effect of pre-travel health advice in general practice. Br J Gen Pract. 1997;47:71-5. 
20. Lestelle C, Aymeric S, Makaroun-Vermesse Z, Pouliquen A, Bernard L, Chandenier J, et al. Impact of advice given to travelers concerning the main infectious risks associated with traveling in the tropics. Med Mal Infect. 2015:45:222-8.

21. Schlagenhauf $P$, Weld L, Goorhuis A, Gautret P, Weber R, von Sonnenburg F, et al. Travel-associated infection presenting in Europe (2008-2012): an analysis of EuroTravNet longitudinal, surveillance data, and evaluation of the effect of the pre-travel consultation. Lancet Infect Dis. 2015;15:55-64.

22. Cullen KA, Arguin PM. Malaria surveillance-United States, 2011. MMWR Surveill Summ. 2013;62:1-17.

23. Laver SM, Wetzels J, Behrens RH. Knowledge of malaria, risk perception, and compliance with prophylaxis and personal and environmental preventive measures in travelers exiting Zimbabwe from Harare and Victoria Falls International airport. J Travel Med. 2001;8:298-303.

24. DePetrillo JC, Singer C, Bergagnini IA, Kolakowski P, Edwards B, Smith MA. Assessment of adherence to atovaquone-proguanil prophylaxis in travelers. J Travel Med. 2010;17:217-20.

25. Goodyer L, Rice L, Martin A. Choice of and adherence to prophylactic antimalarials. J Travel Med. 2011;18:245-9.

26. Belderok SM, van den Hoek A, Roeffen W, Sauerwein R, Sonder GJ. Adherence to chemoprophylaxis and Plasmodium falciparum anti-circumsporozoite seroconversion in a prospective cohort study of Dutch short-term travelers. PLoS ONE. 2013;8:e56863.

27. Wieten RW, Harting J, Biemond PM, Grobusch MP, van Vugt M. Towards improved uptake of malaria chemoprophylaxis among West African travellers: identification of behavioural determinants. Malar J. 2013;2:360.

28. Warne B, Weld LH, Cramer JP, Field VK, Grobusch MP, Caumes E, et al. Travel-related infection in European travelers, EuroTravNet 2011. J Travel Med. 2014;21:248-54.

29. Angell SY, Behrens RH. Risk assessment and disease prevention in travelers visiting friends and relatives. Infect Dis Clin North Am. 2005;19:49-65.

30. Fulford M, Keystone JS. Health risks associated with visiting friends and relatives in developing countries. Curr Infect Dis Rep. 2005;7:48-53.

31. Smith AD, Bradley DJ, Smith V, Blaze M, Behrens RH, Chiodini PL, et al. Imported malaria and high risk groups: observational study using UK surveillance data 1987-2006. BMJ. 2008;337:a120.

32. WHO. World Malaria Report 2015. Geneva: World Health Organization; 2015. http://apps.who.int/iris/bitstream/10665/200018/1/9789241565158_ eng.pdf?ua=1. Accessed 16 Dec 2016.

33. Schlagenhauf $P$, Petersen E. Malaria chemoprophylaxis: strategies for risk groups. Clin Microbiol Rev. 2008;21:466-72.

34. Johansson Arhem KM, Gysin N, Nielsen HV, Surya A, Hellgren U. Low and declining risk for malaria in visitors to Indonesia: a review of local Indonesian and European travelers' data and a suggestion for new prophylactic guidelines. J Travel Med. 2015;22:389-95.
35. Moller CH, David K. Imported malaria is stable from Africa but declining from Asia. Dan Med J. 2014;61:A4827.

36. Boggild AK, Geduld J, Libman M, Yansouni CP, MaCarthy AE, Hajek J, et al. Malaria in travellers returning or migrating to Canada: surveillance report from CanTravNet surveillance data, 2004-2014. CMAJ Open. 2016;4:e352-8.

37. Deutscher Reiseverband (DRV). Travel statistics. South and South East Asia-outbound travel from Germany in 2015. Personal communication.

38. Schlagenhauf $P$, Tschopp A, Johnson R, Nothdurft HD, Beck B, Schwartz E, et al. Tolerability of malaria chemoprophylaxis in non-immune travellers to sub-Saharan Africa: multicentre, randomised, double blind, four arm study. BMJ. 2003;327:1078.

39. Overbosch D, Schilthuis $H$, Bienzle U, Behrens $\mathrm{RH}$, Kain KC, Clarke PD, et al. Atovaquone-proguanil versus mefloquine for malaria prophylaxis in nonimmune travelers: results from a randomized, double-blind study. Clin Infect Dis. 2001;33:1015-21.

40. Toovey S, Nieforth K, Smith P, Schlagenhauf P, Adamcova M, Tatt I, et al. Comparative benefit of malaria chemoprophylaxis modelled in United Kingdom travellers. Travel Med Infect Dis. 2014;12:726-32.

41. Dondorp AM, Newton PN, Mayxay M, Van Damme W, Smithuis FM, Yeung $\mathrm{S}$, et al. Fake antimalarials in Southeast Asia are a major impediment to malaria control: multinational cross-sectional survey on the prevalence of fake antimalarials. Trop Med Int Health. 2004;9:1241-6.

42. Nayyar GM, Breman JG, Newton PN, Herrington J. Poor-quality antimalarial drugs in southeast Asia and sub-Saharan Africa. Lancet Infect Dis. 2012;12:488-96.

43. Hall KA, Newton PN, Green MD, De Veij M, Vandenabeele P, Pizzanelli D, et al. Characterization of counterfeit artesunate antimalarial tablets from southeast Asia. Am J Trop Med Hyg. 2006;75:804-11.

44. Orlandi-Pradines E, Rogier C, Koffi B, Jarjaval F, Bell M, Machault V, et al. Major variations in malaria exposure of travellers in rural areas: an entomological cohort study in western Côte d'Ivoire. Malar J. 2009;8:171.

45. Texier G, Machault V, Barragti M, Boutin JP, Rogier C. Environmental determinant of malaria cases among travellers. Malar J. 2013;12:87.

46. van Genderen PJ, van Thiel PP, Mulder PG, Overbosch D, Dutch Schiphol Airport Study Group. Trends in the knowledge, attitudes and practices of travel risk groups towards prevention of malaria: results from the Dutch Schiphol Airport Survey 2002 to 2009. Malar J. 2012;11:179.

\section{Submit your next manuscript to BioMed Central and we will help you at every step:}

- We accept pre-submission inquiries

- Our selector tool helps you to find the most relevant journal

- We provide round the clock customer support

- Convenient online submission

- Thorough peer review

- Inclusion in PubMed and all major indexing services

- Maximum visibility for your research

Submit your manuscript at www.biomedcentral.com/submit 